\title{
Study of the Protection of Lisu Intangible Cultural Heritage and the Development of Ethnic Village Tourism: An Example of Tongle Village in Weixi County
}

\author{
Lijun Xu \\ School of Southwest Nationalities, Chengdu, China, 610000
}

Keywords: intangible cultural heritage; Lisu; ethnic village tourism

\begin{abstract}
This paper intensively analyzes the protection of the Lisu intangible cultural heritage ““"A Chi Mu Gua"” in Tongle Village and the existing problems in tourism utilization, and discusses how to transform the Lisu intangible cultural heritage from the cultural resource with transformation condition into real economic development and cultural productive force to provide path selection for changing or optimizing the local traditional tourism development concept and the village tourism development.
\end{abstract}

\section{Introduction}

China's intangible cultural heritage is a vast and fertile field with unlimited cultural growth space and market expansion space. The tourism industry has become a world-wide industry, providing opportunities for the development of regional tourism culture. At the same time, intangible cultural heritage has become an important resource for cultural tourism. This article analyzes in depth the problems in the protection and tourism use of the intangible cultural heritage of Tongle Village, and provides a path choice for the change or optimization of local traditional tourism development concepts and the smooth realization of sustainable economic, social and ecological development.

\section{Research Status of "Non-heritage" Protection and Tourism Utilization}

\subsection{Research on "Intangible" Protection and Related Issues.}

Foreign scholars will more often use oral and intangible heritage to name intangible cultural heritage, and its research scope is also more extensive, covering cultural memory, cultural space, oral and intangible cultural heritage. [1] After the "Convention on the Protection of Intangible Cultural Heritage" passed in 2003, a clear definition was made of the intangible cultural heritage, that is, the intangible cultural heritage is considered by all communities, groups and sometimes individuals as its cultural heritage. Composition of various social practices, ideas, expressions, forms of knowledge, knowledge, skills, and related tools, objects, crafts, and cultural venues. [2] And Yi Xiaoli (2014) summarized it as traditional, contemporary, but also lively; inclusive; representative; community-based. [3] In the industrial development research, Liu Jinxiang (2012) believes that there are two kinds of protection methods for "non-heritage", namely rescue protection and development protection. Rescuing protection is government-led and lacks liveliness of "intangible". Therefore, intangible cultural heritage projects that have market potential and development value and are related to consumers' daily cultural life should be introduced into the industrialization development model. Maximize the economic value of its development. [4] Feng Yucai (2012) believes that the cultural industry is not a simple "culture + money." [5] The development and utilization of "intangible heritage" in the context of the development of cultural industries must be followed: First, the first principle embodied in the "Intangible Cultural Heritage Law of China" and the "Convention on the Protection of Intangible Cultural Heritage", ie development must comply with protection. First, we must also observe that not all "intangible cultural heritage" can be used for industrial development and utilization. Even if some cultures can enter the industry, the method and process of entry must still be prudent. [6] 
In the research on productive protection, Chen Huawen (2010) believes that the purpose of productive protection is not to form an industry, but to conserve skills through scale and industrialization. [7] Productive protection can be considered as a way of "intangible" protection in the context of industrialization. However, this culture should not lose its own characteristics in the process of commodity consumption. [8] "Intangible" is the most authentic manifestation of national culture. With the advent of the "Cultural+" era, it is necessary to speed up the construction of a digitalized protection system, promote the inheritance of intangible wisdom, give full play to the advantages of ethnic cultural resources, and integrate rationally. For the industry, to further achieve the coordinated development of culture and economy. [9]

\section{2 "Intangible" Tourism Utilization and Related Issues.}

"Intangible" tourism use has always been a hot topic of "intangible" research. Some scholars will focus their research on the necessity of tourism development. Intangible cultural heritage is regarded by some scholars as a source of creativity and innovation. It connects the past and the future. It has a significant contribution to the advancement of knowledge and the stimulation of economic and social innovation. [10] Lei Rong and Hu Beiming (2012) thought that the development of "intangible" tourism is an important means for the industrialization of cultural heritage. There is a tourism value in the "intangible" and tourism development can be a space for modern survival and development. It also provides necessary funds for the protection of "intangible" protection. [11] Zhao Yue et al. (2013) believe that the current non-heritage research in China requires three major contradictions in the development of non-left heritage tourism, namely, the contradiction between protection and development, the contradiction between development subjects, and among stakeholders. The contradictions were explored in depth. [12] Jing Jingguang (2015) pointed out that in order to truly follow the laws of commodity economy, the creative process of "intangible" should be preserved and its true connotation should be reasonably reflected. [13] Zhu Xi and Ye Xincai (2015) believe that the suitability evaluation of tourism development is a basic forward-looking work for the development of "intangible" tourism. Taking the three towns of Huian as the case, taking the land suitability assessment of FAO as a reference, and combining the evaluation system of traditional tourism resources, a theoretical system for the evaluation of tourism development suitability of "intangible" tourism was constructed to reflect its resource endowments. At the same time, the balance between inheritance protection and tourism development is also taken into consideration. [14]

It is not difficult to find from many research literatures that "untouchable" tourism development is an important way to develop cultural industries and creates considerable economic value, but it is precisely because of the drive of interests that "non-heritage" emerges in tourism development. The problem is the most, it also deserves us to further study and explore a more reasonable and effective way.

\section{Intangible Cultural Heritage of Tongle Village}

Tongle Village is located in Yezhi Town, Weixi Lisu Autonomous County, Diqing Tibetan Autonomous County, Yunnan Province, and is a traditional residential building complex of the Lisu nationality. It is about 700 kilometers away from the provincial government Kunming City, about 300 kilometers from the provincial capital Shangri-La Jiantang, and 83 kilometers away from the county town of Baohe. It is deeply buried in the deep mountains on the edge of the Baima Snow Mountain National Nature Reserve and is located in Sanjiang, a natural and cultural heritage of the world. The heart of the river is about 3 kilometers south of the Li River. Tongle Village is also the most well-preserved village for intangible cultural heritage of the Qiang people. It is the birthplace of the state-level intangible cultural heritage "A Chi Mu Gua"” and the inheritance place of the Dong people's syllable characters. In 2006, the Tongle Dong village was announced as the first batch of provincial-level Qiang heritage conservation zones by the Yunnan Provincial Government; it was listed as one of the top 100 new discoveries in the country in the third national cultural relics survey; January 2012 It was announced by the Yunnan Provincial Government as the seventh batch 
of provincial-level cultural relics protection units in Yunnan Province; in April 2013, it was listed as a soil wind plan, the creation point of the Yunnan Cultural Heritage Model Village.

\subsection{Intangible Cultural Heritage}

"A Chi Mu Gua". In the eyes of the Lisu people in other regions, the Wei people's colony in Weixi County is "Wang Baming." "Wang" means the meaning of the people, "Ba" means the desire or likes, and "Ming" refers to local. He said: "The Lisu people think that the ancestral monkeys and Neolithic people living in Gordon are probably the first of the Lisu people. A branch of the people or the ancestors, and for thousands of years, the Qiang people used Visi as their base camp for three major migrations to Nujiang, Baoshan, Dehong, Linyi, Myanmar, Thailand, and other countries. The Wa people chant songs to catch up with the sun and the moon. Since the Wa people lived in Weixi County for a long time, they have also accumulated a wealth of traditional folk culture. "There is a saying in this place, "Don't eat salt and never live. It is not a matter of life if we do not sing a tune." [15] And in the colorful Lisu songs and dances, "A Chi Mu Gua " is very representative. It is praised as a kind of song and dance that conveys ancient information.

"A Chi Mu Gua " is the meaning of "goat's song and dance" in the Lisu language. "Wood scraping" means sing in idioms. "A Chi Mu Gua shave," also known as "dangdang shave," is a song that sings songs. It is popular in the upper reaches of the Minjiang River, centered on Yezhi County. It is a self-entertaining dance. It does not have an orchestral accompaniment. It is always a dance song. The origin of the "A Chi Mu Gua" was considered by the Lin Daihui, a Lisu culture scholar in Weixi County, as a song and dance created by the ancestors of the Lisu ethnic group in the Weixi region and inherited from generation to generation. This was due to the long-term migration of the local people and the establishment of the sheep. With profound emotions, the Lisu people imitate the movements and voices of the goats and create a kind of bond that expresses mutual emotions. [16]

\subsection{Inheritance of "A Chi Mu Gua".}

The state-level intangible cultural heritage "A Chi Mu Gua” now has 1 representative inheritor of national traditional music "A Chi Mu Gua” rap, "A Chi Mu Gua” song and dance, provincial folk song and dance class "A Chi Mu Gua " is a representative successor of song and dance. Table 1 shows the recommendation of a representative inheritor in 2015.

Table 1 Recommended representative inheritors of the "A Chi Mu Gua” at the provincial intangible cultural heritage in Yunnan Province

\begin{tabular}{|c|c|c|c|c|c|}
\hline Referee & Gender & Location & $\begin{array}{l}\text { Year } \\
\text { of } \\
\text { Birth }\end{array}$ & Master & Master's Profile \\
\hline $\begin{array}{l}\text { Xiong } \\
\text { Wenming }\end{array}$ & Male & $\begin{array}{l}\text { Xinluo } \\
\text { Village }\end{array}$ & 1967 & $\begin{array}{l}\text { Xiong } \\
\text { Ziyi }\end{array}$ & $\begin{array}{l}\text { The national inheritors, male and female, were born in } \\
\text { 1941. The people of Xinluo Village in Yezhi Township } \\
\text { learned the "wood scraping" handed down from } \\
\text { generation to generation by the Weng Ninbo, the } \\
\text { creator of the syllables. It has become an indispensable } \\
\text { core figure near the village festivals or weddings and } \\
\text { funerals. In 2002, the Provincial Department of } \\
\text { Culture and the Provincial Committee of the People } \\
\text { were named as folk musicians. }\end{array}$ \\
\hline $\begin{array}{l}\text { Xiong } \\
\text { Dequan }\end{array}$ & Male & $\begin{array}{l}\text { Tongle } \\
\text { Village }\end{array}$ & 1988 & \multirow{3}{*}{ Li Biqing } & \multirow{3}{*}{$\begin{array}{l}\text { The provincial successor, Ah Qiaodou, male, and Lisu } \\
\text { nationality, was born in } 1968 \text {. He is a famous dance } \\
\text { leader and organiser of Yezhi Town, Yezhi Town, } \\
\text { Weixi County. He was called by the fellow villagers. } \\
\text { "Footings" means "leader". }\end{array}$} \\
\hline Yu Zhiying & Female & $\begin{array}{l}\text { Tongle } \\
\text { Village }\end{array}$ & 1997 & & \\
\hline $\begin{array}{ll}\text { Yu } \\
\text { Guoying }\end{array}$ & Female & $\begin{array}{l}\text { Songluo } \\
\text { Village }\end{array}$ & 1992 & & \\
\hline Yikelu & Female & $\begin{array}{l}\text { Xinluo } \\
\text { Village }\end{array}$ & 1978 & $\begin{array}{l}\text { Yu } \\
\text { Xianjun }\end{array}$ & $\begin{array}{l}\text { Provincial successor, Xinluo Village, Lisu nationality } \\
\text { original singer. }\end{array}$ \\
\hline $\begin{array}{l}\text { Jian } \\
\text { Baoqun }\end{array}$ & Male & $\begin{array}{l}\text { Songluo } \\
\text { Village }\end{array}$ & 1987 & & $\begin{array}{l}\text { Remarks: Learning from the elderly in Songluo } \\
\text { Village }\end{array}$ \\
\hline
\end{tabular}


At present, the intangible "A Chi Mu Gua " has a more complete inheritance mechanism and the main body of the village. In general, the "intangibles" of ethnic villages are maintained in the local common customs and beliefs and blood clan relationships. That is to say, the inheritance of "intangibles" is based on "blood relations" and "acquaintance society". Up. [17] Most of the inheritors of the "A Chi Mu Gua " were apprentices of masters who were handed down from generation to generation, and the inheritors of the national and provincial levels were local masters. It can be seen from the present situation of representative inheritors. In fact, most of the apprentices they choose follow the characteristics of "acquaintance society" and "blood relationship" (Figure 2-1). The same village's masters generally recruit apprentices from the same village to enter the village's performing arts team and become major performers. Most of the apprentices also witnessed their own development. They originally had a certain "scraper" basis for singing and dancing, and then formally studied and trained systematically.

The government is also gradually increasing its support for the inheritance and protection of the "Aqa Sha". Since 2010, departments at all levels have allocated more than 200,000 yuan for the "Aqasha" song and dance training service fee and the student's loss of work time. With the help of the town's cultural station, Xiong Ziyi's "Aqianguasha" rap 9 songs have been collected. Yu Xianjun's "Aqasha" raps 6 songs. Each of Xiong Ziyi and Yu Xianjun's apprentice rap and sings 1 song and 2 songs, and collects teaching materials such as Xiong Ziyi and Yu Xianjun. Each year, the inheritors at various levels will go to the provincial capital to participate in the "intangible" The inheritor's related training is one or two times. During this period, the government will give the inheritors and their apprentices at all levels with subsidies for late work. At the same time, the "Aquban shave" is continuing into the classroom. For example, the provincial successor Li Biqing will enter the campus every Wednesday to carry out the "Aqian Shazhao" professor. In the interview, we can also see that for the "non-left into the campus" activities, he is very positive, and he believes that letting the child touch the "scratch" from a young age, arouses the interest of "a ruler", which can improve them. The awareness of the protection and protection of the "Aqa Sha Gua" can also be used to build and reserve strength for the inheritors while spreading outside.

The difficulties faced by the inheritance. From the perspective of the inheritance of the "Aqianmao" in Tongle Village and even Weixi County, it can be seen from the fact that after summarizing the local conditions after the visit, the members of the "Aqiushu" performing team are basically farmers. That is to say, farming, which forms a farming when you are busy, only in the leisure time will be "wood scraping" learning and participate in "A ruler scraping" phenomenon. The younger generation will choose to go out to work. Even though they have been influenced by the "Ah Ju Sha Sha" since childhood, but because most of the year is not in the village, the lyrics and the pace are gradually becoming unfamiliar. Even many young generations have gradually forgotten these skills. When interviewing the provincial heritage teacher Li Biqing, he could not help but lament: "The current number of people on the show team to call to a certain scale is very difficult. Some need to do farm work, and some need to go out to work, which is also to maintain life. Now few people in the village can only do 'a scrape.' In the past, people often jumped in 'village scrapers.' Nowadays, there are more and more people working and there are more and more people working outside, sometimes they don't come home for the Spring Festival. A phone call was safe, so the atmosphere in the village was not as strong as before.

From the point of view of the social environment in which inheritance protection depends on survival, although the current intangible "A Chi Mu Gua" has a relatively complete inheritance mechanism, but with the young and middle-aged labor force in Tongle Village continuing to work outside, the village will gradually present a "human relationship". The network of "acquaintance society" and "blood relations" used to maintain the development of inheritance will gradually weaken, and the final result may be that no one inherits and no one protects. This phenomenon of weakening has already begun to appear doubtful in Tongle Village.

The predicament faced by the development of village tourism. First, the village has poor accessibility. Due to the constraints of the local fragile environment, traffic conditions, and insufficient efforts to create scenic spots, the tourism reception in Tongle Village has encountered a 
bottleneck. From the main road of Yezhi Town to the junction of Tongle Village, it is an uphill road facing the Lijiang River and backing against the mountains. The path leading to the performing arts venues of Tongle Village rushes onto the road and is surrounded by circles. Apart from entering the mouth of Tongle Village, there is a viewing platform built. There are no other sights along the way. It is sparsely populated and many tourists come. The tourist reception center by the main road looks toward the end of the road into the village, or stops for a short time or gives up directly. The tourists who have traveled to Tongle Village will also have reasons due to inconvenient roads and fewer play items. It is generally not interested to come again. This greatly restricts the development of tourism in Tongle Village.

Secondly, the limitations of the development of the "Aquku Sha" performance team in Tongle Village. Although the performance team will have a certain amount of economic compensation each time they perform, due to the low frequency of screenings and the lack of a single economic compensation, it is not enough to support the daily life of the members of the performance team. Therefore, most members of the performance team are mainly engaged in agriculture. , And will not be off the production of "A ruler scraping" performance. Because of this situation, many performers have to rush to the performance venues from various places or because of busyness, long distances, etc., and the time for convening each time becomes longer and the personnel are not fixed. As a result, the scale of the performance team cannot always be expanded. , And sometimes it will be less with the time of the season, the performance of the game is not able to achieve fixed-point timing. At present, the performance team of Tongle Village has taken team tourists to the scene or made an appointment through a travel agency in advance. It has independently funded and the leader of the performance team has convened to perform the performance of "Ah Ju Sha Sha". Each performance is not priced according to the number of participants and the number of visitors. All of this has led to an increase in the cost of an "Aqa Sha" performance, which has increased the cost of tourists' travel and its attraction to tourists.

\section{Exploring the Development Path of Village Tourism}

\subsection{Follow the Overall Protection Principle.}

To follow the principle of holistic protection is to protect both the song and dance culture itself and its source of life. It is necessary to pay attention to the "past" of culture and pay attention to its "present" development. It is necessary to pay attention to the background and environment in which it arises, but also to integrate and coordinate all aspects of the relationship and its interest claims; also respect the value of the identity and cultural identity of the Lisu people. Although there is a contradiction between concept and reality in the overall protection, in the actual work, we should still minimize the deconstruction protection and preserve its originality as much as possible. At the same time, it should be noted that the overall protection of "intangibles" does not refer to all-embracing protection, but rather takes different measures depending on the priorities of the protected objects.

In terms of the intangible "A Chi Mu Gua” of Tongle Village, the main body of protection includes the government, non-survivors, communities, experts, scholars, and developers. It is necessary to notice the diversity of the protected subjects. Affected by this, there is no shortage of challenges for the overall protection of the "A Chi Mu Gua" in Tongle Village. It is the original intention of Tongle Village to develop "intangible" tourism by expanding the dissemination scope on the basis of protection and promoting the inheritance and development of " A Chi Mu Gua ". However, in practice, it is inevitable that the originality of "intangible" will be ignored due to the pursuit of economic benefits and other reasons. For example, in the interview, this issue was also mentioned. Although the current "A Chi Mu Gua" song and dance performance in Tongle Village is still a traditional form of singing and dancing, the stage performances after going out of the village are mostly due to the pursuit of the stage. Over time, perhaps the original authenticity of "A Chi $\mathrm{Mu}$ Gua" may be lost in the form of an invisible form, forgetting that it was originally a self-entertaining song and dance performance. This requires Tongle Village to make full use of the 
advantages of various protection entities in carrying out "intangible" tourism utilization, and to cooperate in various ways, and to carry out integrated protection in accordance with the actual situation of the protection and protection of the "A Chi Mu Gua”.

\subsection{Introduce the "Cultural +" Concept.}

With the advent of the "Cultural+" era, cultural industries will gradually become one of the leading industries in our society. The ecological system that traditional culture depends on, like Le Village, is still well preserved, and this is its advantage. In the pursuit of coordinated development of culture and economy, we should give full play to the advantages of national culture and rationally integrate existing excellent resources into a cultural industry. Therefore, the protection and use of the intangible "A Chi Mu Gua” in Tongle Village is particularly important.

Integrating with the pace of social development is a new way to effectively protect and utilize intangibles. [19] Based on reality, Tongle Village should try to protect and use the "Internet + intangible” model. Specifically, it is necessary to save, display, and manage information, teaching materials, and video materials related to the inheritance and protection of the intangible " $\mathrm{A} \mathrm{Chi} \mathrm{Mu}$ Gua” of Tongle Village in a digital form. At present, Tongle Village has gradually digitized and preserved data. However, there is no platform that can be displayed, and further work is needed. At the same time, the process of displaying to the public through the Internet is also a process of transmitting the essence of the traditional culture of the Lisu ethnic group. This will help the public understand the traditional culture of the Dong ethnic group and understand the intangible "squeegee". Furthermore, it is possible to attract more tourists to go to Tongle Village to watch the song "A Chi Mu Gua" and to enhance the "intangible" tourism image of Tongle Village and drive the development of the tourism economy of Tongle Village. In addition, you can also understand the cultural needs of the public through data analysis and other means to create an invisible display space that meets the needs.

\subsection{Strengthen Community Participatory Development.}

Participatory development is different from the traditional top-down development model. It emphasizes the participation of bottom-up target groups. It focuses on the development of "people." The core of participatory development is "empowerment", which means increasing the voice of community and ordinary villagers in the development and decision-making right, which is also to benefit the target group. [20] From a practical point of view, the process of empowering social target groups is actually a process that allows them to rebuild self-esteem, so as to awaken their own knowledge and ability to participate in the development of the community and help improve the community.

Taking into account the actual situation of Tongle Village, the best way to protect the heritage of the uninvited "A Chi Mu Gua" is to allow it to be transmitted and passed on. In the past, the usual singing and dancing in the eyes of the villagers has now become a symbol of the village culture. Everyone is proud of the learning experience. It can also be seen that the villagers' recognition of changes in local culture and the recognition of "non-heritage" have continued to increase. As the people of the Lisu nationality continue to increase their sense of cultural identity, their growing interest in the non-heritage "A Chi Mu Gua" can also lead to the gradual expansion of the inheritor team. "A Chi Mu Gua" continues to behave in a benign manner. Expanding the performing team to increase the popularity of the "A Chi Mu Gua " song and dance performance in Tongle Village, in order to accelerate the development of "intangible" tourism in the village, this will more effectively promote the inheritance and protection of the " A Chi Mu Gua ".

\section{Conclusion}

In the sustainable human development system, economic sustainable development is the foundation, and ecological sustainable development is a necessary condition, and sustainable social development is the ultimate goal. [21] Social sustainable development includes the sustainable development of social and cultural life. The inheritance and protection of the intangible "A Chi $\mathrm{Mu}$ 
Gua” of Tongle Village shall be based on the concept of sustainable development, follow the principle of overall protection, strengthen the participatory development of the community, and carry out "Internet +" in the "culture +" horizon. "Intangible" protection and utilization model will enhance Tongle Village's "intangible" tourism image and promote the development of Tongle Village tourism economy.

\section{Acknowledgements}

Fund Project: Ph.D. Program of Innovative Research Projects of Southwest Minzu University (CX2016BS02).

\section{References}

[1] Peter J M N. Masterpieces of Oral and Intangible [J]. Culture Current Anthropology, 2002, 43 (2): 130-148.

[2] An Xuebin, et al. Research on the folk beliefs of ethnic minorities from the perspective of "non-heritage": based on the investigation of the Bai nationality and the Yi nationality of Dali and Chuxiong in Yunnan [M]. Beijing: China Social Sciences Press, 2013.

[3] Yi Xiaoli. Cultural Heritage and Tourism Planning [M]. Beijing: Peking University Press, 2014: 5.

[4] Liu Jinxiang. Non-material cultural heritage should take the road of industrialization [N]. Learning Times, 2012 (6).

[5] Feng Yucai. The current understanding of the protection of intangible cultural heritage requires a unified understanding [J]. Folklore Studies, 2012(4):6.

[6][8] Liu Xuxu, Ma Zhiyao. Review of the research on the intangible cultural heritage of China in 2012[J]. Journal of Changchun Municipal Party School, 2013(6):22.

[7] Chen Huawen. Several issues on the productive protection of intangible cultural heritage[J]. Journal of Guangxi University for Nationalities (Philosophy and Social Science Edition), 2010(5):91.

[9][17][19] Xiao Yuanping, Chief Editor of Chai Li. Development Report on the Intangible Cultural Heritage of Chinese Minority Nationalities. 2016: Overall Protection: Construction and Development of Ethnic Cultural and Ecological Protection Areas [M]. Beijing: Publication of Social Science Literature Society, 2016: 250-255.

[10]Cominelli F, Greffe X. Intangible cultural heritage: Safeguarding for creativity[J]. City, Culture and Society, 2012 (1): 245-248.

[11] Lei Rong, Hu Beiming: Analysis of the Necessity of Intangible Cultural Heritage Tourism Development_—Based on the Perspective of Conservation and Inheritance [J]. Guizhou Ethnic Studies, 2012(2):132-133.

[12] Zhao Yue, Shi Meiyu. Analysis of the Three Contradictions in the Development of Intangible Cultural Heritage Tourism [J]. Tourism Journal, 2013(9): 85-88.

[13] Jing Jingguang: Creativity and authenticity of "intangible” culture in tourism development [J]. Social Scientist, 2015(2):86.

[14]Zhu Yi, Ye Xincai. Research on Suitability Evaluation of Intangible Cultural Heritage Tourism Development: A Case Study of Hui'an Women Gathering Area [J]. Tourism Forum, 2015(3):90-93.

[15] Weixi County CPC Committee Propaganda Department. Weixi! Wei Xi! [M]. Kunming: Yunnan Fine Arts Publishing House, 2009:98.

[16] Yang Lu. The Lisu people's “A Chi Mu Gua ” in the perspective of music anthropology_—A 
case of Tongle Village in Yezhi Town, Weixi County[D]. Kunming: Yunnan Arts Institute, 2015:11.

[18] Liu Kuili. The Integrity Principle of Intangible Cultural Heritage and Its Protection [J]. Journal of Guangxi Teachers College (Philosophy and Social Science Edition), 2004, (4).

[20][21] Wang Jian, Peng Jian. Tourism development in the southwestern minority areas in social interaction [M]. Beijing: China Economic Publishing House, 2014: 73, 75. 